Check for updates

Cite this: RSC Adv., 2019, 9, 8700

Received 17th December 2018

Accepted 10th March 2019

DOI: $10.1039 / c 8 r a 10337 b$

rsc.li/rsc-advances

\section{Enhanced detection of toxicity in wastewater using a 2D smooth anode based microbial fuel cell toxicity sensor $\uparrow$}

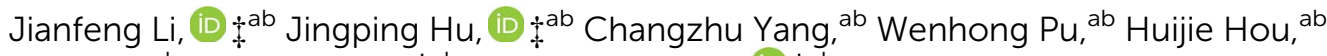 \\ Jikun $\mathrm{Xu}^{\mathrm{ab}}$ Bingchuan Liu ${ }^{\star \mathrm{ab}}$ and Jiakuan Yang (D) *ab
}

\begin{abstract}
As the biological recognition element of microbial fuel cell (MFC) toxicity "shock" sensors, the electrode biofilm is perceived to be the crucial issue that determines the sensing performance. A carbon felt and indium tin oxide (ITO) film anode were utilized to examine the effects of anodic biofilm microstructure on MFC toxicity sensor performance, with $\mathrm{Pb}^{2+}$ as the target toxicant. The carbon felt anode based MFC (CF-MFC) established a linear relationship of $\mathrm{Pb}^{2+}$ concentration $\left(\mathrm{C}_{\mathrm{Pb}^{2+}}\right)$ vs. voltage inhibition ratio $\left(\mathrm{IR}_{2 \mathrm{~h}}\right)$ at a $C_{\mathrm{Pb}^{2+}}$ range of $0.1 \mathrm{mg} \mathrm{L}^{-1}$ to $1.2 \mathrm{mg} \mathrm{L}^{-1}$. The highest $\mathrm{IR}_{2 \mathrm{~h}}$ was only $38 \%$ for CF-MFC. An ITO anode based MFC (ITO-MFC) also revealed a linear relationship between $C_{\mathrm{Pb}^{2+}}$ and $\mathrm{IR}_{2 \mathrm{~h}}$ at $C_{\mathrm{Pb}^{2+}}$ of $0.1 \mathrm{mg} \mathrm{L}^{-1}$ to $1.5 \mathrm{mg} \mathrm{L}^{-1}$ but better sensing sensitivity compared with the CF-MFC. The IR $\mathrm{R}_{2 \mathrm{~h}}$ of ITO-MFC gradually approached $100 \%$ as $\mathrm{C}_{\mathrm{Pb}^{2+}}$ further increased. The enhanced sensing sensitivity for the ITO anode possibly originated from the thin biofilm that resulted in the efficient exposure of exoelectrogens to $\mathrm{Pb}^{2+}$. The employment of 2D conductive metal oxide with a smooth surface as the anode was able to increase the MFC sensing reliability in real wastewater.
\end{abstract}

\section{Introduction}

So far, traditional wastewater treatment plants (WWTPs) mainly operate based on biological treatment processes. Currently, various types of heavy metals and organic toxicants are discharged into the natural environment through industrial waste streams. The discharged toxic water containing heavy metals or other toxicants may cause severe interruption or irreversible damage to the biological process in WWTPs, creating a bottleneck for their deliberate applications. Therefore, a sensor capable of performing continuous on-line monitoring of heavy metals and organic toxicants is urgently needed as an early warning method to provide protection for WWTPs' operation. A microbial fuel cell (MFC) is a bioelectrochemical system that degrades organic matters via anodic exoelectrogens to bring together power production and wastewater treatment in a sustainable and cost-effective manner. ${ }^{1}$ As toxicants can affect the activity of the anode exoelectrogens negatively and lead to sudden drop of MFC voltage output, a prescreening of toxic

\footnotetext{
${ }^{a}$ School of Environmental Science and Engineering, Huazhong University of Science and Technology (HUST),Wuhan, 430074, PR China. E-mail: Bingchuan@hust.edu. cn; jkyang@hust.edu.cn; Fax: +86-27-87792101; Tel: +86-27-87793948

${ }^{b}$ Hubei Provincial Engineering Laboratory of Solid Waste Treatment, Disposal and Recycling, 1037 Luoyu Road, Wuhan, Hubei, 430074, China

$\dagger$ Electronic supplementary information (ESI) available. See DOI: 10.1039/c8ra10337b

$\$$ These two authors contributed equally to this paper.
}

substances in wastewater can be realized with a MFC "shock" toxicity sensor. ${ }^{2}$ Until now, the study of MFC toxicity "shock" sensors were mainly focused on its early warning function towards non-specific bio-toxicity sensing. ${ }^{3-5}$ Compared with traditional water quality detection methods, the prescreening of biotoxins in wastewater with MFC is fast, simple and can be easily performed online as an early warning device. ${ }^{6-8}$

Great efforts have been devoted to enhance the sensing credibility and sensitivity of MFC toxicity sensors. For instance, MFC toxicity sensor with biocathode as the sensing element achieved the lowest detection limit for formaldehyde $(0.0005 \%)$ and avoided interferences from various water quality parameters compared to the traditional anode sensing element. ${ }^{9} \mathrm{~A}$ cathode-shared MFC sensor array was developed to mitigate cathode performance variation and achieved linear correlation between voltage inhibition ratio and $\mathrm{Cu}^{2+}$ concentration from 2 to $6 \mathrm{mg} \mathrm{L}{ }^{-1} \cdot{ }^{10} \mathrm{~A}$ transient-state operation mode MFC sensor greatly enhanced the sensing sensitivity compared with traditional constant external resistance connected mode MFC sensor. ${ }^{11}$ As the biological recognition element of MFC toxicity sensor, anodic or cathode biofilm is the key factor that determines the sensing performance. However, few studies have probed into the correlation of the MFC sensing performance and biofilm characteristics. Study shows that high biomass density and EPS content can weaken sensing sensitivity. ${ }^{12}$ But the in-depth exploration of the influence of biofilm for MFC toxicity sensing has not been conducted so far in the domain of MFC toxicity sensor. 
The microstructures of biofilm could be tailored by the selection of the anode type. Various novel anode materials have been developed, with novel $3 \mathrm{D}$ architectures, ${ }^{13}$ high specific surface area $^{\mathbf{1 4}}$ and unique surface chemical/physical characteristics $^{\mathbf{1 5}}$ to enhance power generation of MFC. The above properties were proved to directly influence anodic biofilm thickness and microstructure. ${ }^{16}$ Indium tin oxide (ITO), on the other hand, has been coated as thin film on glass substrate and studied as electrode material in electrochemical sensors, ${ }^{17}$ biosensors, ${ }^{18}$ thin films synthesis platform for various applications, ${ }^{19,20}$ and substrate for the initiation of biofilm growth ${ }^{21,22}$ or visible spectroelectrochemical characterization. ${ }^{23}$ With its extremely smooth 2D surface, high conductivity and hydrophilicity, ITO-coated MFC anode surface could result in plain and low quantity of biofilm.

The selection of the anode types could lead to different mass transfer characteristics of the target toxicants across the biofilm as well as the availability of the effective sensing sites, thus changing the sensing performance. In this study, we applied an ITO conductive glass as a 2D smooth anode to form a thin layer biofilm aiming at strengthening the sensing sensitivity and linearity of MFC "shock" sensor for real wastewater toxicity detection, with $\mathrm{Pb}^{2+}$ as the target toxic substance. Carbon felt anode was also employed for MFC toxicity sensor as a control test. Carbon felt has been extensively used as a model material for MFC anode since it has 3D porous structures, high biocompatibility and large surface area, ${ }^{\mathbf{1}}$ favorable for growing biofilm and high biomass loading compared with other plain carbon based anode materials. ${ }^{24}$ Subsequently, the sensing performances of MFC toxicity sensors with carbon felt and ITO film anodes were evaluated to correlate with the anode biofilm properties.

\section{Materials and method}

\subsection{MFC toxicity sensor construction and operation}

Single chamber cube MFCs (size: $6 \mathrm{~cm} \times 5 \mathrm{~cm} \times 5 \mathrm{~cm}$ with a working volume of $28 \mathrm{~mL}$ ) made of plexiglass were used as the MFC toxicity sensors in this study. ${ }^{25}$ All MFCs were equipped with an air cathode. ${ }^{26}$ The MFC was fabricated with either a carbon felt or an ITO anode as anode, and denoted as CF-MFC and ITO-MFC, respectively. Each type of MFC sensor was duplicated. The carbon felt and the ITO-coated glass were purchased from CeTech (Taichung, Taiwan) and Huanan Xiangcheng Sci \& Tech Ltd (Shenzhen, China), respectively. The anode/cathode position in the MFC sensors follows our previous study. ${ }^{25}$ The anode and cathode were connected via a titanium wire with an external resistance $\left(R_{\text {ext }}: 1000 \Omega\right)$. The voltage output of the MFC sensors was collected by a Keithly 2750 Data Acquisition System every 30 min during the MFC startup and stabilization period, and every $1 \mathrm{~min}$ during toxicity shock test.

Prior to the tests, all MFC anodes were acclimated in batch mode with municipal wastewater (chemical oxygen demand (COD): $250-350 \mathrm{mg} \mathrm{L}^{-1}$ ) taken from the influent of a local municipal wastewater treatment plant in Wuhan, Hubei province, China. The anodes were considered fully acclimated when the voltage output was stable and repeatable through three consecutive cycles (Fig. S1†). After acclimation, anodic solutions were replaced by synthetic wastewater for the following electrochemical tests and morphological characterization. The synthetic wastewater was prepared by dissolving $0.3 \mathrm{~g}$ anhydrous sodium acetate (NaAc), $5 \mathrm{~mL}$ vitamin solution and $12.5 \mathrm{~mL}$ trace minerals solution in $1 \mathrm{~L} 50 \mathrm{mM}$ phosphate buffer solution (PBS) containing $\mathrm{NH}_{4} \mathrm{Cl} 0.31 \mathrm{~g} \mathrm{~L}{ }^{-1}, \mathrm{Na}_{2} \mathrm{HPO}_{4} 4.576 \mathrm{~g}$ $\mathrm{L}^{-1}, \mathrm{NaH}_{2} \mathrm{PO}_{4} 2.772 \mathrm{~g} \mathrm{~L}^{-1}, \mathrm{KCl} 0.13 \mathrm{~g} \mathrm{~L}^{-1} \cdot{ }^{27}$ For toxicity shock test, anodic solutions were replaced by real wastewater containing $0.3 \mathrm{~g} \mathrm{~L}^{-1} \mathrm{NaAc}$ aiming at practical application.

\subsection{Toxicity shock test}

The toxicity shock tests were conducted by directly injecting lead nitrate standard solution (1000 $\mathrm{mg} \mathrm{L}^{-1}$, Guobiao (Beijing) Testing\& Certification Co. Ltd) using micropipettes (Eppendorf) into the MFC sensors. The restriction set by China Ministry of Environmental Protection for $\mathrm{Pb}^{2+}$ discharge concentration from wastewater treatment plant is $0.1 \mathrm{mg} \mathrm{L}^{-1}$ (GB18918-2016). Thus, the $\mathrm{Pb}^{2+}$ shocks were examined from low concentrations to high concentrations at $0.1,0.3,0.5,1.0,2.0$ and $3.0 \mathrm{mg} \mathrm{L}^{-1}$, by injecting 2.8, 8.4, 14, 28, 56 and $84 \mu \mathrm{L} \mathrm{Pb}^{2+}$ standard solution into each sensor, respectively. As free $\mathrm{Pb}^{2+}$ could potentially react with organic matter in wastewater and form precipitate at certain $\mathrm{pH}$ range, the concentration of free $\mathrm{Pb}^{2+}$ in the wastewater was measured using inductively coupled plasma-optical emission spectroscopy (ICP-OES, Optima 8300, PerkinElmer, USA) after the introduction of $\mathrm{Pb}^{2+}$ (Table $\left.\mathrm{S} 1 \dagger\right)$. The $\mathrm{pH}$ of the wastewater before and after 1.0 and $2.0 \mathrm{mg} \mathrm{L}^{-1} \mathrm{~Pb}^{2+}$ injections were presented in Table $\mathrm{S} 2 . \dagger$ The results indicated that the $\mathrm{pH}$ and free $\mathrm{Pb}^{2+}$ concentrations before and after the $\mathrm{Pb}^{2+}$ shock tests were stable. After each $\mathrm{Pb}^{2+}$ shock test, the anode solution was replaced with fresh wastewater (containing $300 \mathrm{mg} \mathrm{L}^{-1}$ sodium acetate) for the recovery of anode microbes. ${ }^{5}$

\subsection{Analytical methods}

The pristine anodes and anodes with biofilms were inspected by SEM (Nova NanoSEM 450). The pretreatment of the anode materials prior to SEM followed the method described elsewhere. ${ }^{28}$ Elemental analysis of $\mathrm{Pb}^{2+}$ across anodic biofilms was conducted by energy dispersive X-ray spectroscopy (EDX). The hydrophilic-hydrophobic property of pristine anodes was examined by a water contact angle analyzer (JC2000D1, POWEREACH, Shanghai). Nitrogen adsorption and desorption isotherm using the Brunauer-Emmett-Teller (BET) method (JW-BK122W, Beijing JWGB SCI \& Tech Co. Ltd., Beijing) were employed for the quantification of the anodes relative surface area and porosity. After the $\mathrm{Pb}^{2+}$ shock tests, CLSM (VK-X200K, KEYENCE, Japan) was conducted for anodic biofilm thickness measurement. EIS analysis of the anode materials were conducted using a VSP-300 Multi potentiostat (Bio-Logic Science Instruments, France) for evaluating the electron transfer resistance of the anode biofilms. The EIS was conducted in the frequency range of $100 \mathrm{kHz}$ to $1 \mathrm{mHz}$ with an $\mathrm{AC}$ modulation amplitude of $10 \mathrm{mV}$, with the anode as the working electrode, the cathode as the counter electrode, and the $\mathrm{Ag} / \mathrm{AgCl}$ as the 
reference electrode. Prior to EIS analysis, all MFCs were operated at open circuit for an hour.

\section{Results and discussion}

\subsection{Surface properties of the pristine anodes}

The morphology of anode has major influence on its biofilm loading capacity ${ }^{29}$ and the anodic electron transfer efficiency. ${ }^{30}$ The pristine carbon felt and ITO film exhibited distinct morphological differences (Fig. S2a and $\mathrm{b} \dagger$ ). Carbon felt showed complex structure and large inner space, while ITO film exhibited smooth surface, and free of visible pores. This discrepancy may be a trigger for the generation of varied biofilm. The XRD analysis was conducted to examine the composition of anode (Fig. S3†). The water contact angles of the pristine carbon felt and the pristine ITO film were $104.25^{\circ}$ and $43.16^{\circ}$, respectively (Fig. S2c and $\mathrm{d} \dagger$ ). Apparently, the pristine ITO film showed better hydrophilic property compared to the counterpart, revealing faster formation of electroactive biofilm achieved on its surface. ${ }^{31}$

\subsection{BET measurement}

Consistent with the SEM observation (Fig. S2 $\dagger$ ), the relative surface areas of the carbon felt anode $\left(40.35 \mathrm{~m}^{2} \mathrm{~g}^{-1}\right)$ was much larger than the ITO anode $\left(1.09 \mathrm{~m}^{2} \mathrm{~g}^{-1}\right)$ (Fig. S4 $\dagger$ ). The adsorption-desorption curves of the carbon felt followed a Type II isotherm, reflecting a typical physical adsorption process on macroporous adsorbents. ${ }^{32}$ The ITO film was complied with a Type III isotherm. Unlike carbon felt, the adsorptiondesorption curves of ITO film did not have an inflection point, indicating an adsorption process on non-porous metal oxide surface (ITO surface). As the pristine carbon felt had large inner space and much larger surface area for microbial adhesion and EPS formation, it should have much higher biofilm loading compared with ITO anode. ${ }^{16}$ This speculation was further evidenced by the anodic biofilm characterizations in the following discussion.

\subsection{Voltage responses of MFC sensors to $\mathrm{Pb}^{2+}$ shocks}

As same voltage baselines of CF-MFC and ITO-MFC cannot be guaranteed due to different capability of power productions for the two anode materials, evaluating the sensor performance solely using the absolute value of the voltage drop was not adequate. ${ }^{12,33,34}$ Therefore, voltage inhibition ratio $\left(\mathrm{IR}_{2 \mathrm{~h}}\right)$ caused by $\mathrm{Pb}^{2+}$ shocks was utilized to represent the "sensor signal change" for the sensor performance evaluation, which is defined as the ratio of the voltage drop $(\Delta V)$ to the MFC voltage baseline at 2 hours after $\mathrm{Pb}^{2+}$ shocks. $\mathrm{IR}_{2 \mathrm{~h}}$ can be expressed with the following equation:

$$
\mathrm{IR}_{2 \mathrm{~h}}=\left(V_{\mathrm{b}}-V_{t}\right) / V_{\mathrm{b}}
$$

where $V_{\mathrm{b}}$ is the voltage baseline value and $V_{t}$ is the voltage 2 hours after $\mathrm{Pb}^{2+}$ shocks. The correlations between $\mathrm{Pb}^{2+}$ concentrations $\left(C_{\mathrm{Pb}^{2+}}\right)$ and $\mathrm{IR}_{2 \mathrm{~h}}$ for ITO-MFC and CF-MFC were quite different as shown in Fig. 1 . The average $\mathrm{IR}_{2 \mathrm{~h}}$ of ITO-MFC was 3.9 times that of CF-MFC, indicating ITO-MFC had an excellent sensing performance over CF-MFC. ITO-MFC had a 2D smooth plane anode biofilm (Fig. 2 and 3) so that most exoelectrogens could be more easily exposed to wastewater toxicities (e.g. $\left.\mathrm{Pb}^{2+}\right)$, and most of the exoelectrogens were affected within a short period of time. On the contrary, CF-MFC had more complex biofilm structure, and exoelectrogens at different positions could not be fully exposed to $\mathrm{Pb}^{2+}$ in a short time period. For ITO-MFC, the $\mathrm{IR}_{2 \mathrm{~h}}-C_{\mathrm{Pb}^{2+}}$ revealed a linear relationship $\left(R^{2}=0.9407\right.$; slope is 40.18$)$ at the $C_{\mathrm{Pb}^{2+}}$ of $0.1-1.5 \mathrm{mg} \mathrm{L}^{-1}$ (Fig. 1b). As $C_{\mathrm{Pb}^{2+}}$ further increased, $\mathrm{IR}_{2 \mathrm{~h}}$ gradually approached $100 \%$ indicating that most of the exoelectrogens in ITO biofilm were effectively inactivated.

$\mathrm{IR}_{2 \mathrm{~h}}-C_{\mathrm{Pb}^{2+}}$ of CF-MFC also exhibited a sensing linearity $\left(R^{2}=\right.$ 0.9727; slope is 30.52) for $C_{\mathrm{Pb}^{2+}}$ of $0.1-1.2 \mathrm{mg} \mathrm{L} \mathrm{L}^{-1}$ and the $\mathrm{IR}_{2 \mathrm{~h}}$ began to slightly decrease when $C_{\mathrm{Pb}^{2+}}$ was higher than $1.2 \mathrm{mg} \mathrm{L}^{-1}$. The highest $\mathrm{IR}_{2 \mathrm{~h}}$ reached $38 \%$ for CF-MFC while $\mathrm{IR}_{2 \mathrm{~h}}$ of ITO-MFC could reach nearly $100 \%$. This may be attributed to different transport kinetics of $\mathrm{Pb}^{2+}$ in the two sensors. The steeper linearity of $\mathrm{IR}_{2 \mathrm{~h}^{-}} C_{\mathrm{Pb}^{2+}}\left(C_{\mathrm{Pb}^{2+}}\right.$ of $\left.0.1-1.5 \mathrm{mg} \mathrm{L}{ }^{-1}\right)$ for ITO-MFC indicated higher sensitivity over CF-MFC and faster transport kinetics of $\mathrm{Pb}^{2+}$ that efficiently suppressed the activity of exoelectrogens. As is the inherent sensing characteristics for MFC toxicity sensor, IR could not increase indefinitely with the increase of $C_{\mathrm{Pb}^{2+}}$, and could only approach $100 \%$ when all anode exoelectrogens are inhibited by $\mathrm{Pb}^{2+}$. Thus, the sensing linearity could only exists when $C_{\mathrm{Pb}^{2+}}$ is below a critical value. In this study, IR of ITO-MFC gradually increased to close to $100 \%$ showing high sensing efficiency towards $\mathrm{Pb}^{2+}$. In comparison, the highest IR value for CF-MFC was only $38 \%$, indicating that the exoelectrogens responsible for power production in CF-MFC could not be effectively exposed to $\mathrm{Pb}^{2+}$. The average sensitivity of ITO-MFC was 3.9 times that of CF-MFC. The higher $I_{2 h}$ of ITO-MFC indicated the anode exoelectrogens of ITO-MFC were exposed to $\mathrm{Pb}^{2+}$ more effectively over CF-MFC. Apparently, ITOMFC exhibited better sensing sensitivity over CF-MFC. The data of MFC voltage recovery with wastewater and $300 \mathrm{mg} \mathrm{L}^{-1}$ sodium acetate after $\mathrm{Pb}^{2+}$ shocks (Fig. $\mathrm{S} 5 \dagger$ ) indicated that both MFC sensors had good reusability.

\subsection{Morphological characterization of anode biofilm}

The disparities $\mathrm{IR}_{2 \mathrm{~h}}-C_{\mathrm{Pb}^{2+}}$ relationships of CF-MFC and ITOMFC revealed different $\mathrm{Pb}^{2+}$ transport and adsorption kinetics on biofilm, which can be further confirmed by morphological characterization of anodic biofilm by CLSM (Fig. S6 $\dagger$ ) and SEM (Fig. 2). The CLSM showed that the biofilm acclimated on ITO anode surface exhibited smooth morphology and the average biofilm thickness was only less than $10 \mu \mathrm{m}$. The surface of ITO anode was flat and dense with almost no pore structure. The low specific surface area of the ITO film had limited space for microbial growth and led to the formation of uniformly smooth biofilm (Fig. 2b). SEM of the cross section of ITO anode biofilm also revealed a thin biofilm formation with only one or two layers of cells (Fig. 3b). The exoelectrogens of the thin biofilm were efficiently exposed to $\mathrm{Pb}^{2+}$ shocks, thus explaining the 

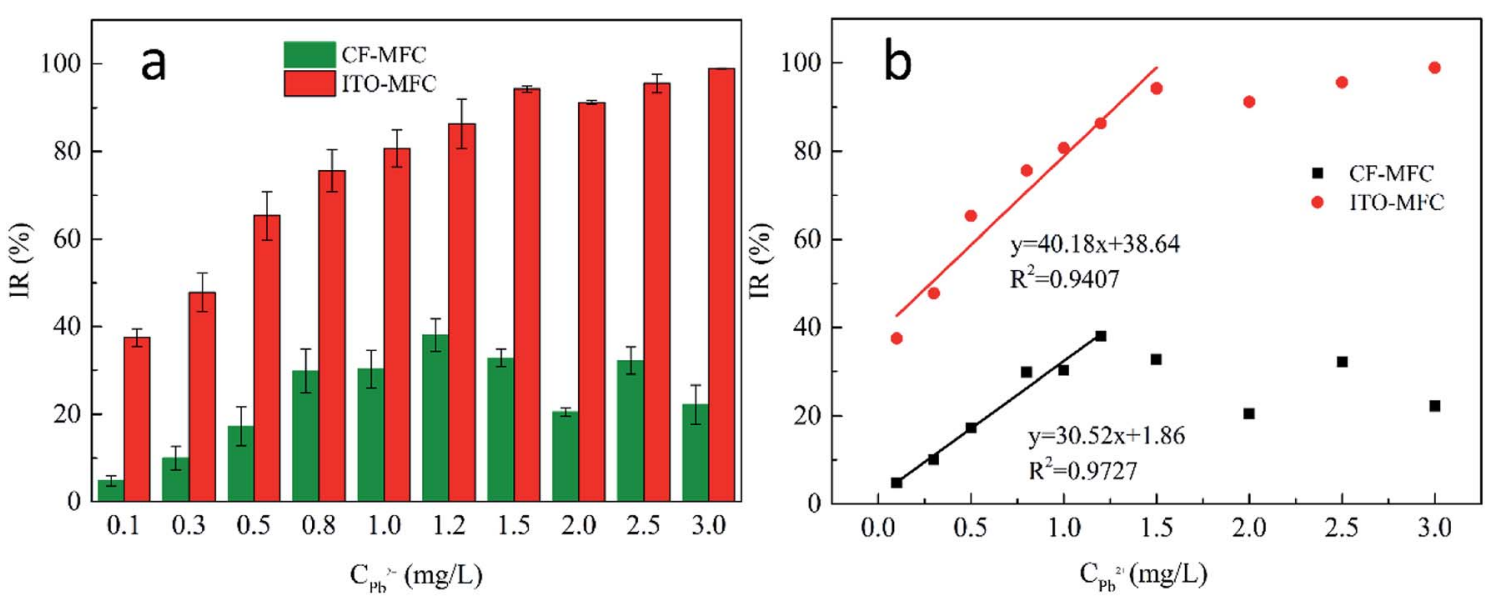

Fig. 1 (a) The IR $2 \mathrm{R}_{2 \mathrm{C}}-\mathrm{C}_{\mathrm{Pb}^{2+}}$ relationship of CF-MFC and ITO-MFC in real wastewater test and (b) the corresponding calibration plot of CF-MFC and ITO-MFC for $\mathrm{Pb}^{2+}$ detection (error bars in (a) were derived from two parallel MFC $\mathrm{Pb}^{2+}$ shock tests in CF-MFC and ITO-MFC; calibration plot in (b) was derived from the average $\mathrm{IR}_{2 \mathrm{~h}}$ from two parallel $\mathrm{Pb}^{2+}$ shock tests in CF-MFC and ITO-MFC).

higher $\mathrm{IR}_{2 \mathrm{~h}}$ of ITO-MFC and enhanced sensing sensitivity (Fig. 1b).

As evident from the SEM images (Fig. 2a), biofilm are abundantly and non-uniformly grown on the carbon felt anode. The carbon felt exhibited an intricate three-dimensional structure with a loose and porous interior as a consequence of intertwined carbon fibers. In addition, the surface of carbon fibers was rough. Thus, the inhomogeneous biofilm was formed on the surface of carbon fibers. While some microbes directly attached to the carbon felt surface would easily be exposed to the bulk solution (red rectangles in Fig. 2a), for most part, the inner layer of microbes were covered with thick biofilm rich in EPS. The thick biofilm acted as the protection layer (Fig. 3a and c) and alleviated the toxic effect of $\mathrm{Pb}^{2+}$ to the inner layer of anode exoelectrogens attaching to the anode surface (red solid rectangle in Fig. 2a). Thus, CF-MFC had a lower sensing sensitivity and the complex biofilm structures led to an erratic $\mathrm{IR}_{2 \mathrm{~h}}$ variation at $C_{\mathrm{Pb}^{2+}}$ higher than $1.2 \mathrm{mg} \mathrm{L}{ }^{-1}$ (Fig. 1). On the contrary, only plain layer biofilm with microbes embedded can be observed on ITO anode surface (Fig. S2b $\dagger$ and $2 \mathrm{~b}$ ) and most of the exoelectrogens were directly exposed to $\mathrm{Pb}^{2+}$ shocks, which explains well for the higher sensing sensitivity of ITOMFC.

\subsection{Distributions of $\mathrm{Pb}^{2+}$ in anodic biofilms after $\mathrm{Pb}^{2+}$ shocks}

The $\mathrm{Pb}^{2+}$ distribution across anodic biofilms of CF-MFC and ITO-MFC were examined using EDX at 2 hours after the $3 \mathrm{mg} \mathrm{L}{ }^{-1} \mathrm{~Pb}^{2+}$ shocks. The $\mathrm{Pb}^{2+}$ concentrition distribution (Fig. $3 \mathrm{c}$ and d) well corresponded to the spatial distribution of the biofilms (Fig. 3a and b), indicating the presence of $\mathrm{Pb}^{2+}$ through out the biofilms. In addtion, for CF-MFC with multilayer biofilm anodes, due to the mass transfer resistance from the complex anode structure, the distribution of $\mathrm{Pb}^{2+}$ on each layer of biofilm was uneven. For ITO-MFC, $\mathrm{Pb}^{2+}$ are distributed
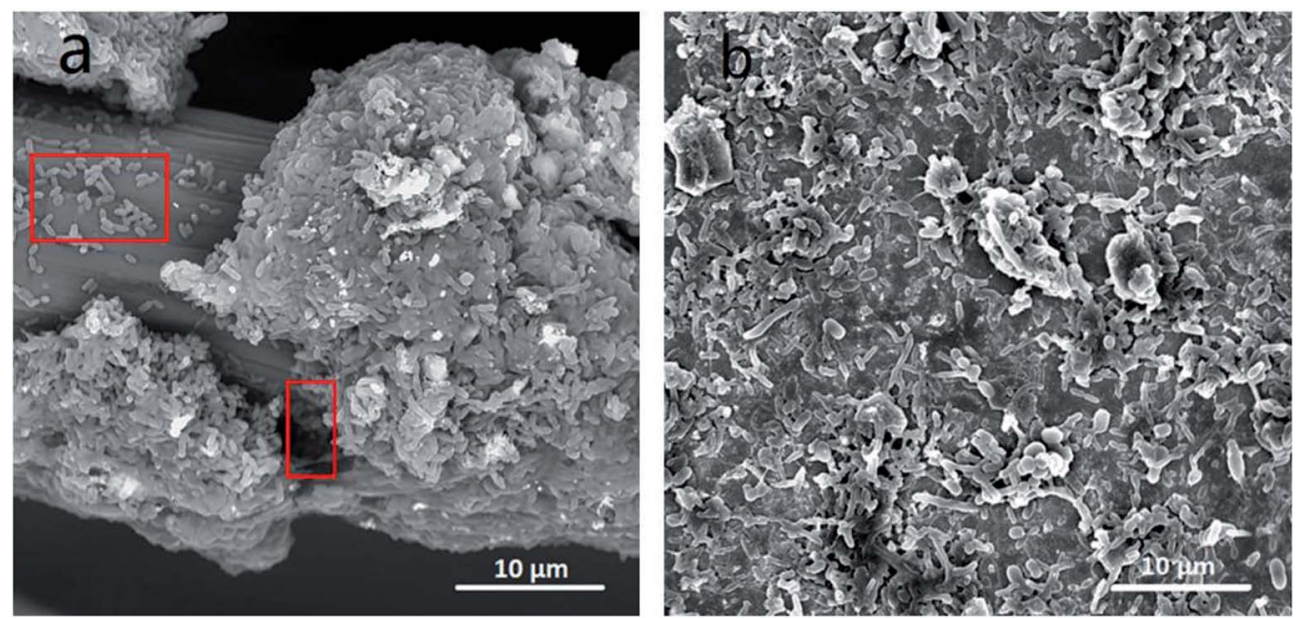

Fig. 2 SEM images of anodes with biofilm. (a) Carbon felt and (b) ITO film. Red rectangles in (a): anode exoelectrogens attaching to anode surface. 

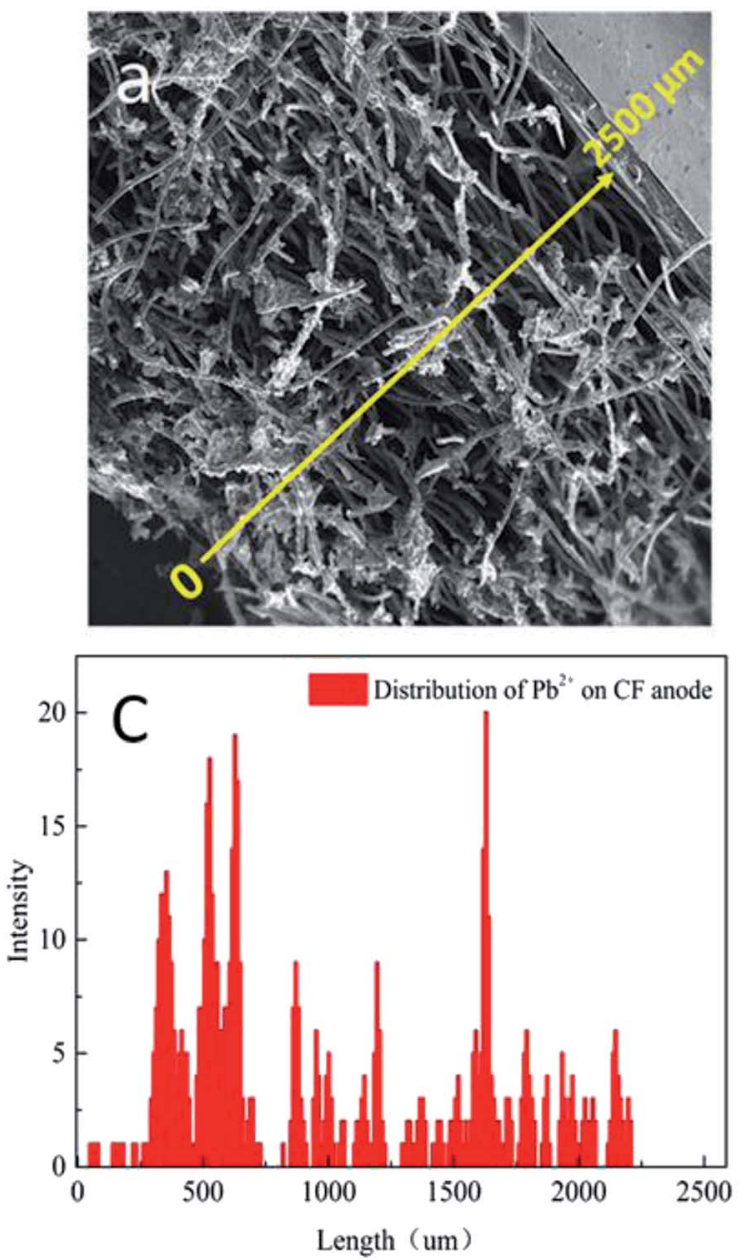
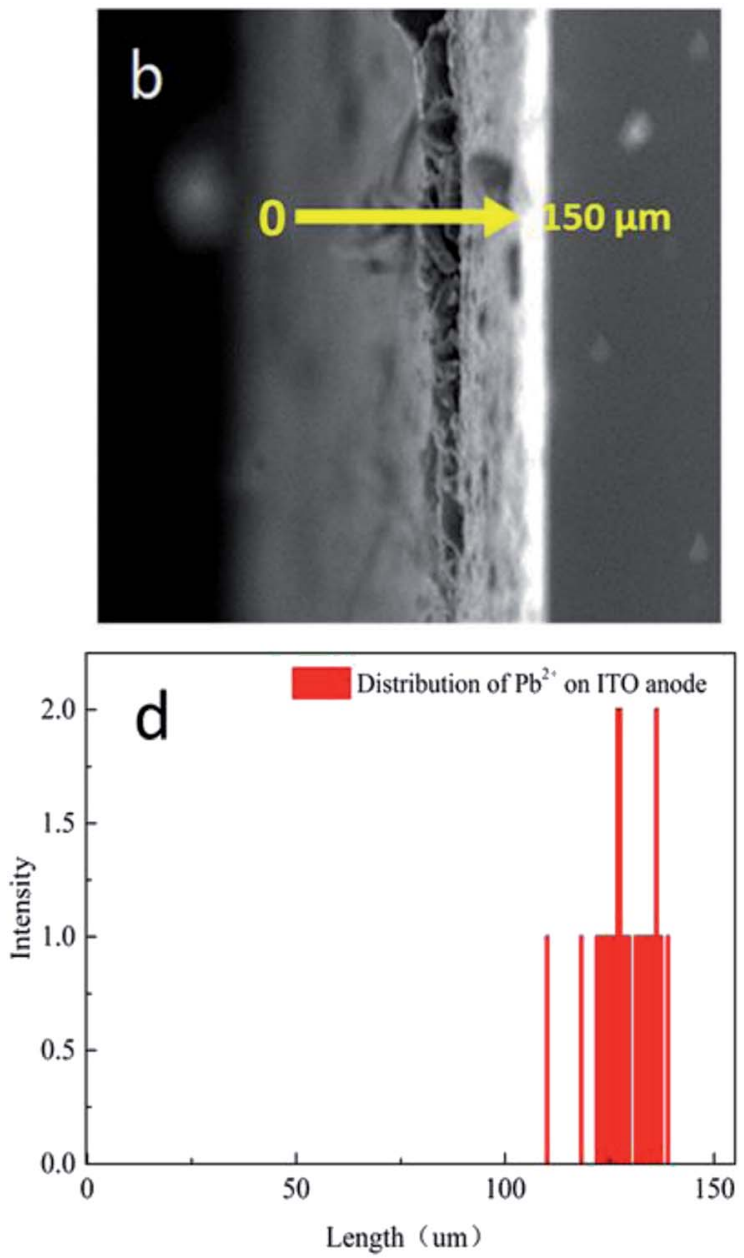

Fig. 3 SEM of the cross-sections of anode with biofilm (a) carbon felt, (b) ITO film; $\mathrm{Pb}^{2+}$ analysis by EDX: (c) carbon felt anode and (d) ITO anode.

relatively uniformly in thin monolayer biofilm. The different $\mathrm{Pb}^{2+}$ distribution characteristics well explains the discrepancy of the sensing patterns of the two anode types (Fig. 1). The $\mathrm{Pb}^{2+}$ concentration in carbon felt anode biofilm was more than 10 times higher than that in ITO anode biofilm (Fig. 3c and d). BET showed that the surface area of carbon felt used in this study was 40 times higher than that of ITO film, leading to higher biofilm loading on carbon felt anode that attracted more $\mathrm{Pb}^{2+}$ from the bulk solution.

\subsection{EIS analysis of the anodes}

EIS analysis of the anode biofilms was conducted using PBS as electrolyte to evaluate electron transfer efficiencies across the biofilm surface (Fig. 4). The impedance spectra typically include a semicircle portion at high frequency region representing the charge transfer impedance at the electrode interface and a linear portion at low frequency region corresponding to the diffusion limited process or mass transfer process. ${ }^{28}$ The EIS spectra for the pristine anodes can be fitted into the equivalent circuit as shown in Fig. 4a, where $R_{\mathrm{S}}$ represents the ohmic resistance, $R_{\mathrm{ct}}$ represents the charge transfer resistance on pristine anode surface and $R_{\text {biofilm }}$ represents the charge transfer resistance across biofilm. ${ }^{28}$ The EIS spectra of the pristine ITO anode only had linear portion, indicating extremely low $R_{\mathrm{ct}}$ at the interface, while the $R_{\mathrm{ct}}$ for the pristine carbon felt anode was $43 \Omega$. For anodes with biofilm, a large semicircle appeared on the EIS spectra of the ITO anode indicating the biofilm formation caused a significant increase in $R_{\mathrm{ct}}$ (about $7000 \Omega$, Fig. $4 \mathrm{~b})$. Interestingly, the $R_{\mathrm{ct}}$ of acclimated carbon felt surface only increased to $175 \Omega$ (inset of Fig. $4 \mathrm{~b}$ ). The EIS analysis provided insights into the dynamic changes of the kinetic resistance of the bioelectrochemical reactions on MFC anode surface which was called as anode polarization resistance. ${ }^{35,36}$ High metabolic activity of the exoelectrogens (abundant biofilm) on MFC anode could greatly decrease the anode polarization resistance, while less exoelectrogens (plain biofilm) will increase the anode polarization resistance. ${ }^{35,37}$ The anode polarization resistance can be identified in EIS spectra as $R_{\mathrm{ct}}$. Thus, the dramatic increase of $R_{\mathrm{ct}}$ for the ITO anode with biofilm (7000 $\Omega$ ) and the small increase of $R_{\mathrm{ct}}$ for the carbon felt anode with biofilm (175 $\Omega$ ) complies well with the higher amount of the metabolic exoelectrogens on carbon felt anode.

\subsection{Significance of this work}

An eligible sensor should establish a linear correlation between the concentrations of analytes and signal output, so that the 

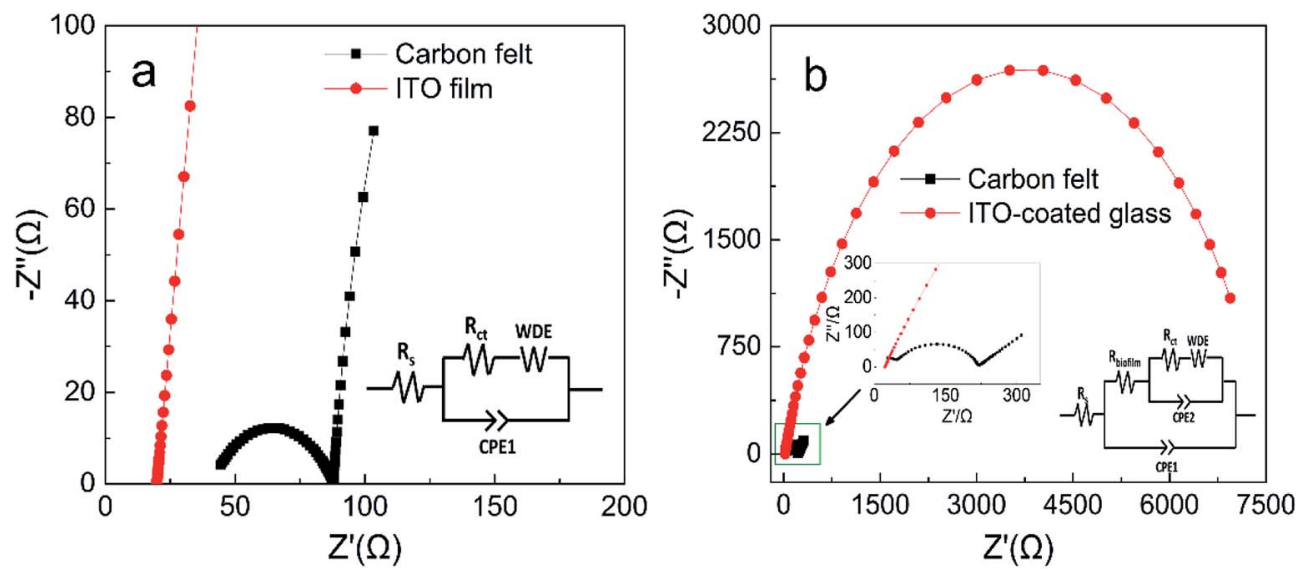

Fig. 4 Nyquist plots of anodes with PBS: (a) pristine anodes and (b) anodes with fully acclimated biofilm (insets: equivalent circuit model).

concentrations of analytes can be quantified. In this study, the ITO anode exhibits smooth 2D surface, low specific surface area, high hydrophilicity, forming plain layer biofilm during MFC operation compared to conventional carbon felt. It exhibited better sensing performance for MFC toxicity "shock" sensor over carbon felt, as most anode exoelectrogens attached to anode surface could be exposed to low levels of $\mathrm{Pb}^{2+}$ shocks, leading to higher sensing sensitivity and $\mathrm{IR}_{2 \mathrm{~h}}$ close to $100 \%$ at higher $C_{\mathrm{Pb}^{2+}}$. On the contrary, carbon felt anode based MFC toxicity sensor exhibited low $\mathrm{Pb}^{2+}$ sensing sensitivity. The highest $\mathrm{IR}_{2 \mathrm{~h}}$ was only $38 \%$. This is possibly because the abundant and layered distribution of biofilms on carbon felt anode alleviated the toxic effect of $\mathrm{Pb}^{2+}$ to the exoelectrogens attaching to anode surface. The exoelectrogens in 3D porous anodes could not be exposed to toxins at the same time due to the spatial distribution. Hence, the spatial complexity of carbon felt anode biofilms hindered the quantitative sensing of toxins with MFC "shock" sensor.

In summary, this study for the first time investigated the correlation of anodic biofilm micro-architecture with sensing performance of MFC shock sensor, as well as the manipulation of biofilm characteristics with different types of anode substrates (ITO film and carbon felt). It was found that the employment of 2D conductive metal oxide (e.g. indium tin oxide) with smooth surface as MFC anode was able to facilitate the formation of smooth and thin layer biofilm, which increased the sensing sensitivity and linearity of the toxicity in real wastewater. When compared to the commercial MFC sensor, HATOX-2000, developed by the KORBI Co., Ltd. (Korea), the ITO-MFC biosensor of our study was possessed of better sensitivity. The IR of our ITO-MFC biosensor towards $0.5 \mathrm{mg} \mathrm{L}^{-1}$ $\mathrm{Pb}^{2+}$ was approximately 3 times of that of HATOX-2000 (65\% vs. $22.6 \%$ ). In addition, ITO-MFC biosensor could effectively detect $0.1 \mathrm{mg} \mathrm{L}^{-1} \mathrm{~Pb}^{2+}$ while the HATOX-2000 could only create response when $\mathrm{Pb}^{2+}$ is higher than $0.5 \mathrm{mg} \mathrm{L}^{-1} .^{38}$

\section{Conclusions}

Herein, we investigated the effects of anodic biofilm on the sensing performance of MFC toxicity "shock" sensor by using two distinct anode materials, carbon felt and ITO film. It was found that both sensors could effectively examine $0.1 \mathrm{mg} \mathrm{L}^{-1}$ or higher $\mathrm{Pb}^{2+}$ shocks in wastewater. Both ITO-MFC and CF-MFC achieved linear sensing sensitivity at low $C_{\mathrm{Pb}^{2+}}$. $\mathrm{IR}_{2 \mathrm{~h}}$ gradually reached near $100 \%$ for ITO-MFC as $C_{\mathrm{Pb}^{2+}}$ increased but only reached $38 \%$ for CF-MFC then slightly decreased. The average sensitivity of ITO-MFC was 3.9 times that of CF-MFC, showing much higher sensitivity in toxicity detection in real wastewater. The combined analysis revealed that thin layer anodic biofilm and two-dimension low anode surface area were the determining factors for enhanced sensing performance, which were more conducive to mass transfer.

\section{Conflicts of interest}

There are no conflicts to declare.

\section{Acknowledgements}

The authors would like to express their gratitude for the financial support for this research from Natural Science Foundation of China (21607046), General program of Natural Science Foundation of Hubei Province (2016CFB538), Innovative and Interdisciplinary Team at HUST (0118261077) and Independent Innovation Foundation of HUST-Exploration Fund (2016YXMS291). The authors would like to thank the Analytical and Testing Center of Huazhong University of Science and Technology for providing the facilities to conduct SEM, and the Advanced Manufacturing and Technology Experimentation Center, School of Mechanical Science \& Engineering, Huazhong University of Science and Technology, for providing the facilities for CLSM analysis.

\section{References}

1 B. E. Logan, B. Hamelers, R. Rozendal, U. Schröder, J. Keller, S. Freguia, P. Aelterman, W. Verstraete and K. Rabaey, Environ. Sci. Technol., 2006, 40, 5181-5192.

2 X. C. Abrevaya, N. J. Sacco, M. C. Bonetto, A. Hilding-Ohlsson and E. Corton, Biosens. Bioelectron., 2015, 63, 591-601. 
3 Y. Jiang, X. Yang, P. Liang, P. Liu and X. Huang, Renew. Sustain. Energy Rev., 2018, 81, 292-305.

4 G. H. Wang, C. Y. Cheng, M. H. Liu, T. Y. Chen, H. Min-Chi and C. Ying-Chien, Sensors, 2016, 16, 1272.

5 J. Yong, L. Peng, C. Zhang, Y. Bian, X. Yang, H. Xia and P. R. Girguis, Bioresour. Technol., 2015, 190, 367-372.

6 T. Li, X. Wang, L. Zhou, J. K. An, J. H. Li, N. Li, H. W. Sun and Q. X. Zhou, ACS Sens., 2016, 1, 1374-1379.

7 Z. Xu, B. Liu, Q. Dong, Y. Lei, Y. Li, J. Ren, J. McCutcheon and B. Li, Bioresour. Technol., 2015, 197, 244-251.

8 Z. H. Xu, Y. C. Liu, I. Williams, Y. Li, F. Y. Qian, H. Zhang, D. Y. Cai, L. Wang and B. K. Li, Biosens. Bioelectron., 2016, 85, 232-239.

9 Y. Jiang, P. Liang, P. Liu, D. Wang, B. Miao and X. Huang, Biosens. Bioelectron., 2017, 94, 344-350.

10 Y. Jiang, P. Liang, P. Liu, X. Yan, Y. Bian and X. Huang, Int. J. Hydrogen Energy, 2017, 42, 4342-4348.

11 Y. Jiang, P. Liang, P. Liu, B. Miao, Y. Bian, H. Zhang and X. Huang, Environ. Sci.: Water Res. Technol., 2017, 3, 472-479.

12 Y. Shen, M. Wang, I. S. Chang and H. Y. Ng, Bioresour. Technol., 2013, 136, 707-710.

13 X. Xie, L. B. Hu, M. Pasta, G. F. Wells, D. S. Kong, C. S. Criddle and Y. Cui, Nano Lett., 2011, 11, 291-296.

14 Y. Qiao, S. J. Bao, C. M. Li, X. Q. Cui, Z. S. Lu and J. Guo, ACS Nano, 2008, 2, 113.

15 Y.-R. He, X. Xiao, W.-W. Li, G.-P. Sheng, F.-F. Yan, H.-Q. Yu, H. Yuan and L.-J. Wu, Phys. Chem. Chem. Phys., 2012, 14, 9966.

16 B. Li, J. Zhou, X. Zhou, X. Wang, B. Li, C. Santoro, M. Grattieri, S. Babanova, K. Artyushkova, P. Atanassov and A. J. Schuler, Electrochim. Acta, 2014, 134, 116-126.

17 L. Wang, Electrochem. Commun., 2004, 6, 225-229.

18 T. Ahuja, Rajesh, D. Kumar, V. K. Tanwar, V. Sharma, N. Singh and A. M. Biradar, Thin Solid Films, 2010, 519, 1128-1134.

19 J. Arjomandi, D. Raoufi and F. Ghamari, J. Phys. Chem. C, 2016, 120, 18055-18065.

20 Y. Liu, N. Wang, C. T. Yang and W. C. Hu, Ceram. Int., 2016, 42, 11411-11416.
21 A. E. Inglesby, K. Yunus and A. C. Fisher, Phys. Chem. Chem. Phys., 2013, 15, 6903-6911.

22 A. Okamoto, K. Hashimoto, K. H. Nealson and R. Nakamura, Proc. Natl. Acad. Sci. U. S. A., 2013, 110, 7856-7861.

23 A. Jain, G. Gazzola, A. Panzera, M. Zanoni and E. Marsili, Electrochim. Acta, 2011, 56, 10776-10785.

24 Y. M. Sun, J. C. Wei, P. Liang and X. Huang, Bioresour. Technol., 2011, 102, 10886-10891.

25 B. Liu, Y. Lei and B. Li, Biosens. Bioelectron., 2014, 62, 308314.

26 W. L. Yang, W. H. He, F. Zhang, M. A. Hickner and B. E. Logan, Environ. Sci. Technol. Lett., 2014, 1, 416-420.

27 A. Baudler, I. Schmidt, M. Langner, A. Greiner and U. Schröder, Energy Environ. Sci., 2015, 8, 2048-2055.

28 R. Karthikeyan, B. Wang, J. Xuan, J. W. C. Wong, P. K. H. Lee and M. K. H. Leung, Electrochim. Acta, 2015, 157, 314-323.

29 S. L. Zhao, Y. C. Li, H. J. Yin, Z. Z. Liu, E. X. Luan, F. Zhao, Z. Y. Tang and S. Q. Liu, Sci. Adv., 2015, 1, e1500372.

30 Y. Yuan, S. Zhou, Y. Liu and J. Tang, Environ. Sci. Technol., 2013, 47, 14525-14532.

31 K. Guo, S. Freguia, P. G. Dennis, X. Chen, B. C. Donose, J. Keller, J. J. Gooding and K. Rabaey, Environ. Sci. Technol., 2013, 47, 7563-7570.

32 M. Thommes, K. Kaneko, A. V. Neimark, J. P. Olivier, F. Rodriguez-Reinoso, J. Rouquerol and K. S. W. Sing, Pure Appl. Chem., 2015, 87, 1051-1069.

33 X. Wang, N. Gao and Q. Zhou, Biosens. Bioelectron., 2013, 43, 264.

34 D. Yu, L. Bai, J. Zhai, Y. Wang and S. Dong, Talanta, 2017, 168, 210-216.

35 R. P. Ramasamy, Z. Ren, M. M. Mench and J. M. Regan, Biotechnol. Bioeng., 2008, 101, 101-108.

36 G. Reguera, K. P. Nevin, J. S. Nicoll, S. F. Covalla, T. L. Woodard and D. R. Lovley, Appl. Environ. Microbiol., 2006, 72, 7345-7348.

37 K. Rabaey, N. Boon, S. D. Siciliano, M. Verhaege and W. Verstraete, Appl. Environ. Microbiol., 2004, 70, 5373-5382.

38 J. S. Lee, D. S. Kim, H. J. Jeon, B. S. Park, H. J. Yang, M. S. Hyun and M. Kim, Ninth International Conference on Sensing Technology, 2015, pp. 416-419. 